\title{
Correction to: Dynamic analysis of antidumping using impulse responses: a case between the United States and China
}

\author{
Yeo Joon Yoon ${ }^{2} \cdot$ Wongi $\mathrm{Kim}^{1}$ \\ Published online: 4 January 2022 \\ () Springer-Verlag GmbH Germany, part of Springer Nature 2021
}

\section{Correction to: Empirical Economics https://doi.org/10.1007/s00181-021-02160-x}

In the original publication of the article, the author "Yeo Joon Yoon" was not indicated as first author. The author "Yeo Joon Yoon" should be the first author. Wongi kim is corresponding author.

The original article has been corrected.

Publisher's Note Springer Nature remains neutral with regard to jurisdictional claims in published maps and institutional affiliations.

The original article can be found online at https://doi.org/10.1007/s00181-021-02160-x.

Wongi Kim

wgkim@sungshin.ac.kr

Yeo Joon Yoon

yjyoon94@gmail.com

1 Department of Economics, Sungshin Women's University, Donam-Sujung Campus, 2-34 da-gil, Bomun-ro, 02844 Seoul, Seongbuk-gu, Republic of Korea

2 Department of Economics, Pusan National University, 2, Busandaehak-ro 63beon-gil, 46241 Busan, Geumjeong-gu, Republic of Korea 